\title{
Burnout among call center staff in the Rabat Sale Kenitra Region
}

\author{
Drissi $E .^{\mathbf{1}}$, Boulbaroud $S^{2}$, Hami $H^{3}{ }^{3}$, Ahami $A .^{1}$, and Azzaoui $F-Z .^{1}$ \\ 1.Unit of Cognitive and Behavioral Neuroscience and Nutritional Health, Faculty of Science, Kenitra, Morocco. \\ 2.Polydisciplinary Faculty, Sultan Moulay Sliman University, Morocco. \\ 3.Laboratory of Genetics and Biometry,Faculty of Science, Kenitra, Morocco.
}

Key words: Burnout, Call centers, employees, Morocco

\begin{abstract}
In Morocco, burnout remains a syndrome that is very little managed, but which nevertheless remains present and significantly affects the aids professions such as call center's teleadvisors. The aim is to study burnout among call center staff in the Rabat, Sale and Kenitra Region using Maslash's three-dimensional model by detecting the socioeconomic factors that influence it. This study involved 121 individuals (59 men and 62 women) who responded to the MBI and to an informative questionary developed by us. The subjects have a minimum age of 22 years and a maximum age of 60 years and an average age of $31.74 \pm 7.93$. On the one hand, 13 subjects $(10.74 \%)$ have a high risk of burnout, high scores of emotional exhaustion and depersonalization, and low personal achievement. The results of the gender impact were not significant. On the other hand, burnout is rarer in older age groups, which suggests that the experience of age would have a protective effect. Spirituality and sport could also have a protective effect. Burnout, very common in the aid professions, must be prevented in companies screened and taken care of by mental health professionals.
\end{abstract}

\section{Introduction}

The concept of burnout or burnout syndrome, was introduced in 1970 by the English psychiatrist Herbert Freudenberger, reporting the difficulties encountered in new management structures: the free clinics.

The professional burnout would rather touch hyperactive or hyper-maniacal "rocket-individuals", so rigorous for themselves and demanding in their obligation of results that they would exhaust their energy to the point of burning from the inside like machines.

Burnout is defined by three dimensions, evolving successively:

- Emotional Exhaustion (EE) or psychological fatigue, with a feeling of depression which makes it irritable and whose physical consequences are non-specific somatic disorders. Emotional exhaustion is little or not improved by rest.

- Dehumanization or depersonalization of the relationship (DP) or loss of interest towards the beneficiary of the service (patient, client, etc.), considered as impersonal objects and no longer as individuals; this relational dehumanization or depersonalization of the relationship (DP) or loss of interest towards the beneficiaries of the service (patient, client, etc.), considered as impersonal objects and no longer as individuals; this relational dryness is the core of the syndrome.

- the decrease in personal achievement (PA), experienced as a sense of professional failure.

It is a specific disease that can occur in a healthy subject: the disease of the helping relationship. Thus, burnout can affect all so-called "contact" professions, in particular health professionals (doctors and nurses, etc...), teachers, police officers, telephone operators, etc.
In a comparative study of call center jobs versus others jobs, the authors found higher scores of emotional dissonance among call center employees [1]. They also point out that call centre employees show significantly higher burnout scores than those in other occupations.

In Morocco, to our knowledge and at the limit of our analysis of the literature, we did not find any studies on burnout among call center staff, for this, we conducted a survey among this population in the Rabat Sale Kenitra Region. This research allowed us to see the extent of occupational stress in this type of workers.

The present study aims to demonstrate the presence of burnout in a supposedly stressed population such as call center staff, by highlighting the various socio-economic factors involved in this phenomenon.

\section{Methods:}

A questionary gathering different socio-demographic and economic information was given to the subjects of the study.

The Maslash Burnout Inventory MBI:The Burnout Inventory Test (original version) was used as a tool to measure burnout, which is one of the descriptive models of burnout, which assesses psychological harm at work by studying the consequences of chronic stress [2]. This original version of the MBI, Maslash Burnout Inventory contains 22 questions that allow to explore 3 dimensions : Emotional Exhaustion (how the person apprehends his work), Dehumanization (his ability to manage the relationship with others) and Personal Achievement at work.

The study involved 121 participants working in call centers in the Rabat Sale Kenitra Region with an age 
between 22 and 60 . The inclusion criterias were limited to volunteering and a seniority of one year, while our protocol excluded subjects with a history of psychological disorders, post traumatic stress, depression or anxiety; In addition, subjects under drug treatment (anxiolytics or antidepressants...) were also excluded.

The statistical analysis of the data was done using the SPSS software version 19 to calculate the averages and standard deviations, and to make correlations between the different parameters. We also used:

- Descriptive analysis with two variables: qualitative and quantitative;

- A bivariate analysis using two statistical tests the student test and the Anova test to compare the averages.

The significance threshold has been set at 5\%, a correlation is considered significant if the $\mathrm{p}$ value is less than 0.05 .

\section{Results:}

\subsection{Sociodemographic profile of the subjects:}

121 subjects were interviewed according to the above criteria, of which $48.78 \%(\mathrm{n}=59)$ are Men and 51.24\% $(\mathrm{n}=62)$ are Women.

The average age of our participants was $31.74 \pm 7.93$, with a minimum age of 22 and a maximum age of 60 . The distribution by age group is divided into four different classes as follows : the [20,30] inclues $47.93 \%$ of ours ample, the $[31,40]$ inclues $33,06 \%$, the $[41,50]$ inclues $11,57 \%$ and the classe of the over 51 years old inclues $7,44 \%$ of our sample.

Table 1 gives the breakdown of the personnel studied by function occupied shows that $46 \%$ of our sample are teleconsultants.

Table1.Distribution of the sample by function occupied.

\begin{tabular}{lcc} 
Functions & Workforce & Percentage \\
\hline Administration & 5 & 4.1 \\
Account Executive & 3 & 2.5 \\
Project Leader & 6 & 5.0 \\
Coach & 6 & 5.0 \\
Coordinator & 6 & 5.0 \\
Data miner & 3 & 2.5 \\
Business Expert & 8 & 6.6 \\
Trainer & 6 & 5.0 \\
Marketing Manager & 3 & 2.5 \\
HR & 3 & 2.5 \\
Supervisor & 10 & 8.3 \\
Help desk technician & 3 & 2.5 \\
Computer Technician & 3 & 2.5 \\
Fax Operators & 56 & 46.3 \\
Total & 121 & 100
\end{tabular}

When it comes to physical exercise, $57.02 \%$ do not do it, while $42.98 \%$ participate have a regular one.

The distribution of the participants according to their prayer practice shows that $15.7 \%$ of the sample do not pray while $84.3 \%$ practice.

\subsection{MBI:}

According to the figure below, it is noted that (38.02\%) of the subjects in our study have moderate emotional exhaustion, (35.54\%) have high emotional exhaustion and $(26.45 \%)$ have low emotional exhaustion.

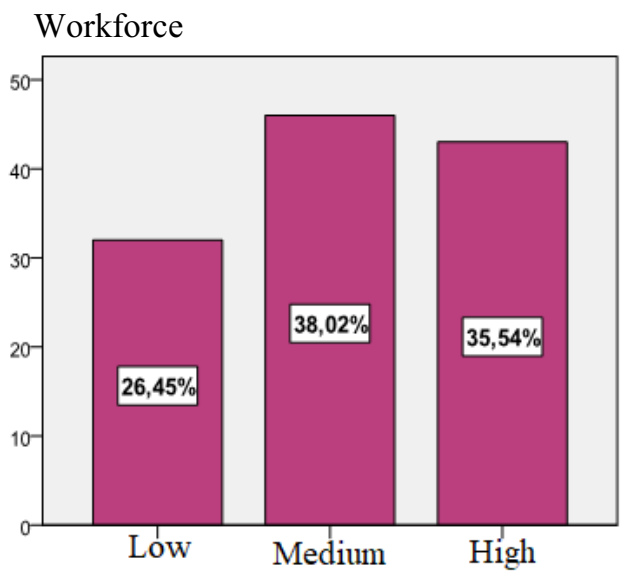

Fig.4. Emotional exhaustion score

The following figure shows that $38.84 \%$ have a low dehumanization score, $34.71 \%$ have a moderate dehumanization score and $26.45 \%$ have a high dehumanization score.

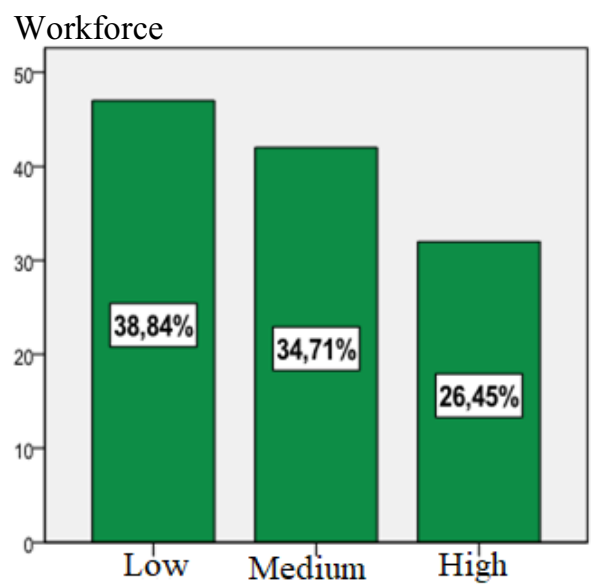

Fig.5. Dehumanization Score

The review of the figure below shows that $47.93 \%$ of our sample has a low professional achievement score, $39.67 \%$ has a moderate professional achievement score and $12.4 \%$ has a high professional achievement score. 
Workforce

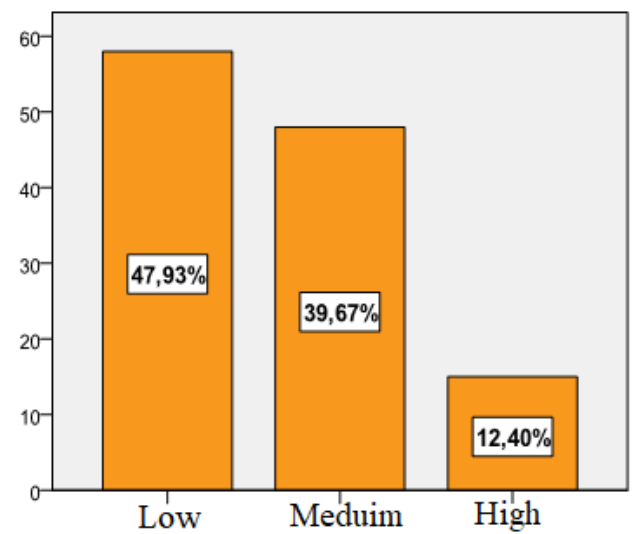

Fig.6. Personal Achievement Score

After examining the scores of the three dimensions of the Maslash test, it was noted that 13 subjects $(10.74 \%)$ had a high risk of having a burnout, 04 men and 09 women, i.e they had high scores of Emotional Exhaution and Dehumanization and a low score of Personal Achievment.

\subsection{Bivariate analyses:}

Table2. Burnout scores by age group

\begin{tabular}{cccc}
$\begin{array}{c}\text { Age } \\
\text { groups }\end{array}$ & $\begin{array}{c}\text { Emotional } \\
\text { Exhaution } \\
\text { (High) }\end{array}$ & $\begin{array}{c}\text { Dehumanization } \\
\text { (High) }\end{array}$ & $\begin{array}{c}\text { Personal } \\
\text { achievement } \\
\text { (Low) }\end{array}$ \\
\cline { 2 - 4 } $20 \_30$ & 37,93 & 31,03 & 43,1 \\
$31 \_40$ & 35 & 30 & 55 \\
$41 \_50$ & 35,71 & 14,29 & 50 \\
51 and & 22,22 & 0 & 44 \\
over & $\mathrm{P}=0,791$ & $\mathrm{P}=0,017$ & $\mathrm{P}=0,473$
\end{tabular}

The statistical difference was noted at the level of dehumanization where the highest percentage is recorded for $20 \_30$ years $31.03 \%$, this score decreases successively in the other age groups. (Table 2)

Table 3. Burnout scores by gender. dimension it is the men who have the highest score with $28.81 \%$. There were also no statistically significant differences. (Table 3)

Table 4. Burnout scores by function within the company

\begin{tabular}{lccc}
$\begin{array}{l}\text { Current } \\
\text { function }\end{array}$ & EE High & DP high & PA low \\
\cline { 2 - 4 } administration & 20 & 0 & 40 \\
$\begin{array}{l}\text { account } \\
\text { manager } \\
\text { project leader }\end{array}$ & 33,33 & 33,33 & 66,67 \\
Coach & 16,67 & 50 & 66,67 \\
Coordinator & 16,67 & 16,67 & 66,67 \\
data miner & 33,33 & 0 & 33,33 \\
trade expert & 37,5 & 25 & 62,5 \\
Trainer & 16,67 & 16,67 & 100 \\
$\begin{array}{l}\text { marketing } \\
\text { manager }\end{array}$ & 0 & 33,33 & 66,67 \\
HR & 33,33 & 66,67 & 33,33 \\
$\begin{array}{l}\text { Supervisor } \\
\text { helpdesk }\end{array}$ & 33,33 & 33,33 & 33,33 \\
technician \\
$\begin{array}{l}\text { computer } \\
\text { technician }\end{array}$
\end{tabular}

According to the table, it is noted that Tele-advisors are distinguished by an increased Emotional Exhaustion of $44.64 \%$. No statistically significant differences were noted. (Table 4)

Table5. Burnout scores and physical exercise.

\begin{tabular}{cccc}
$\begin{array}{c}\text { Regular } \\
\text { physical } \\
\text { exercise }\end{array}$ & \multicolumn{3}{c}{ Burnout 03 dimensions score $(\%)$} \\
\cline { 2 - 4 } Oui & EE High & DP High & PA bas \\
Non & 26,93 & 25 & 15,38 \\
& 42,03 & 27,54 & 10,14 \\
& $\mathrm{P}=0,022$ & $\mathrm{P}=0,724$ & $\mathrm{P}=0,024$
\end{tabular}

It is noted that for the high Emotional Exhaution dimension and the low Personal Achievment it is the women who have the highest percentage, respectively

$41.93 \%$ and $54.84 \%$; While for the high Dehumanization

$\begin{array}{cccr}\text { Male } & 28,81 & 28,81 & 40,7 \\ \text { Female } & 41,93 & 24,19 & 54,84 \\ & \mathrm{P}=0,216 & \mathrm{P}=0,455 & \mathrm{P}=0,067\end{array}$


It was noted that subjects who do not participate in regular physical activity had a higher percentage of Emotional Exhaution $42.03 \%$ with a statistically significant difference $\mathrm{p}=0.022$. The same for high Dehumanization with $27.54 \%$ and with a statistically significant difference $\mathrm{p}=0.724$. Low Personal achievement is highest among who regularly performing physical exercise with $15.38 \%$ and a statistically significant difference $p=0.024$. (Table 5)

Table 6. Burnout scores and prayer practice.

Burnout 03 dimensions score $(\%)$

\begin{tabular}{cccc}
$\begin{array}{c}\text { Prayer } \\
\text { practice }\end{array}$ & EE (High) & DP (High) & PA (Low) \\
\cline { 2 - 4 } Yes & 34,31 & 23,53 & 44,12 \\
No & 42,11 & 42,11 & 68,42 \\
& $\mathrm{P}=0,687$ & $\mathrm{P}=0,047$ & $\mathrm{P}=0,024$
\end{tabular}

It was found that the highest score in high Emotional Exercise is recorded in subjects who do not pray with $42.11 \%$ and the difference is not statistically significant $\mathrm{p}=0.687$. The highest Dehumanization score is recorded among subjects who don't pray with $42.11 \%$ and the difference is statistically significant $\mathrm{p}=0.047$. The highest low Personal achievement score is recorded in nonspraying subjects with $68.42 \%$ and the difference is statistically significant $\mathrm{p}=0.024$. (Table 6)

\section{Discussion:}

Morocco is a country in full economic development, its working environment has de facto turned into a huge anthill where hard work is the key word. Indeed, the workload in Moroccan companies in general and in call centers in particular, becomes such as to generate psychological suffering and acute stress. Burnout, a phenomenon that is much talked about but little known, erodes the psychological health of workers who endure chronic and permanent stress. Unfortunately there is no study in morocco that deals with the mental health of call center staff. Our work therefore covers 121 individuals working in call centers in the Rabat Sale Kenitra Region, including 59 men and 62 women.

Furthermore, our study showed that emotional exhaustion and dehumanization decreased with age, while personal achievement increased with age from the 31-40 to 51 years old and over. The difference was significant only for dehumanization. This dehumanization result indicates a certain emotional dryness among our participants who will tend to dislike their clients less over time. Marianne Guinaud's study showed that there is a significant difference between age and dehumanization on the one hand and personal achievement on the other: the older the residents, the higher the achievement and the lower the depersonalization [3]. The other studies explained the finding that burnout decreased with age by the fact that with experience, the individual may have learned to better manage his stress. Concerning the impact of gender on the appearance of burnout, Our study had found on the one hand, more emotional exhaustion in women and a lack of personal achievement, on the other hand more depersonalization in men. However, the differences were not significant. Most researches had found high depersonalization among men; Truchot's study showed that men had a higher depersonalization score than women, as did others researchers $[4,5,6,7]$. At the same time, C. Maslch refers to the fact that the different components of the syndrome could be unequally distributed according to sex: women would suffer more Emotional Exhaustion and lack of personal accomplishment while men would dehumanize relationships (consistent with our results) [8]. Several explanations are reported to shed light on this difference in outcome between the two sexes concerning depersonalization: D.Truchot attributes this to the difference in socialization of roles according to sex: women have, during their childhood, more maternal roles" and men more "male" roles, according to E. D. Ogus, it is more "emotionally aware" attitudes that protect women from depersonalization $[9,10]$. In contrast, men have more instrumental attitudes. In addition, unlike women, men are less likely to seek social support during hardships, which can be a risk factor for burnout.

On the other hand, participants working as tele-advisors had a higher emotional exhaustion compared to other functions, but the correlation was not significant. This can be explained by :

- Higher workload ;

- The empathy that tele- advisors need to demonstrate.

For Maslach, and for most authors, emotional exhaustion would be the key component of the syndrome. It's the dimension that triggers the two other.

In our study sport significantly decreases emotional exhaustion $(\mathrm{p}=0.022)$, as well as depersonalization, (not significant result) The Glasberg and al study found that burnout was higher among physicians who did not engage in physical activity or recreation, and this finding was statistically significant [11]. The moderating effect of exercise on stress has been studied less often than other variables. Two aspects of exercise were considered: physical activity and fitness level. Physical activity can be defined as the movement of the body (motor skills) accompanied by muscle contractions resulting in a certain energy expenditure and including leisure physical activity, occupational physical activity and domestic physical activity [12]. Fitness refers to the body's adaptation to physical activity, including all exerciseinfluenced systems (including the cardio-respiratory system) [12]. Initially studies focused on fitness level (fitness hypothesis) to explain the moderating effect of exercise on stress. These studies generally analyze the protective effect on stress of aerobic fitness that is determined by both physical activity and genetic factors [13]. This hypothesis postulates that responses to stress in 
the sympathetic cardiovascular and nervous systems would be mitigated by improved fitness [14]. But most of this research, usually carried out in the laboratory, often produces contradictory results [15]. It has been shown that fitness alone does not explain the psychological benefits of exercise. For example, cross-sectional studies show that fitness and mood are not highly correlated [16]. In addition, other studies have shown an improvement in mood after a physical exercise program with no change in fitness level [17]. These results suggest that other mechanisms are involved to explain the protective effect of exercise on stress. Physical activity that allows us to escape a stressful event, to recharge our batteries, provides a period of respite [18]. This hypothesis simply requires being physically active and not necessarily well trained. Being physically active through physical activity can also affect mood and well-being by providing a sense of accomplishment.

Our study found that participants who practiced prayer had a low rate of dehumanization $\mathrm{p}=0.047$ and a high rate of personal achievement $\mathrm{p}=0.024$. Moreover, emotional exhaustion was low among practitioners (result not significant). The study by Alice Badoux et al demonstrated the importance of spirituality in reducing burnout and work-related pain in palliative care nurses [19]. Recall that some studies have shown that high levels of spirituality are associated with low levels of stress [20, $21,22]$ or that spirituality moderates the effects of stress on different variables of physical or mental health $[23,24,25]$. Although a relationship has been observed between these two constructs, spirituality, mainly feeling connected to its values and being able to give meaning to its life, usually only partially explains the level of stress [21]. In some cases, spirituality was negatively associated with stress only for certain types of factors (life partner and family) [26]. Other studies have not found a relationship between the level of spirituality or religion and stress [27], although spirituality moderates the relationship between self-esteem and stress. Spirituality could therefore influence how individuals perceive themselves. Thus, the authors underline the importance of examining the role that individuals attribute to spirituality in their lives or their level of satisfaction with it, rather than just the level of spirituality (e.g., its degree of importance). These differences in perceptions may also help to explain the differences observed between men and women in the role of spirituality in coping with stress. Finally, studies have shown that under certain conditions spirituality can be associated with a higher level of distress, depression [28]. These recent studies have highlighted, as mentioned above, the importance of knowing individuals perception of spirituality. Indeed, spirituality can be perceived positively or negatively depending on a person's interpretation of it and their lived experiences [29].

\section{Conclusion:}

Burnout is a syndrome which remains unknown. Most of the models that studied it agree that it results from an imbalance between resources, expectations and reality at work.
In fact it continues to exhaust the mental health of workers under stress in particular the staff of the call centers especially the tele-advisors who are so permanently in contact with the customer that they get emotionally involved and become vulnerables. Analysis of Maslash test results has shown on the one hand, women are more subject to burnout than men, even if the results are not significant after examining the scores of the three dimensions of the Maslash test 13 subjects $(10.74 \%)$ have a high risk of having a burnout, 04 men and 09 women, i.e. they have high scores in Emotional Exhaution and Dehumanization and a low score in Personal Achievement. On the other hand, burnout is more rare in older age groups, which suggests that the experience of aging has a protective effect.

Light has also been shed on the practice of sport and spirituality, which have shown factors that diminish and protect against burnout.

Finally the burnout must be more publicized because it is a scourge that costs our societies a lot through absenteeism and presenteeism. So prevention and management are essential through the dispatch of mental health experts and occupational psychologists who will be able to detect on time and propose adequate solutions.

\section{Acknowledgements :}

We warmly thank the 121 call centre employees who agreed to answer the questionnaires, without whom our work would not have been possible.

\section{References:}

1. D. Zapf, S. Einarsen, H. Hoel, \& M. Vartia, Empirical findings on bullying in the workplace In International Perspectives in Research and Practice. (pp. 103-126). London: Taylor \& Francis (2003)

2. S. E.Jackson, and C.Maslach,. 'Job stress among helping professionals: The effects on workers and their families'. Presented at the Research Workshop on Current Issues in Occupational Stress: Theory, Research, and Intervention, Downsview, Ontario, (1980)

3. M.Guinauld Evaluation du burnout chez les internes de médecine générale et étude des facteurs associés, Th : Méd. : Créteil, (2006)

4. C.Vaquin-villeminey, Prévalence du burnout en médecine générale : enquête nationale auprès de 221 médecins généralistes du réseau Sentinelles, Thèse de doctorat en médecine général, Université René Descartes (2007)

5. M.Cabellero \& al., Prevalence and factors associated with burnout in health area. Aten Primaria, 31; 27(5): 313-7. (2001)

6. G. Kevin \& al, Burnout in psychiatric nursing. Blackwell Science Ltd, Journal of Advanced Nursing, 34(3), 383-396 (2001) 
7. D. Truchot, Le burnout des médecins libéraux de champagne Ardenne, rapport de recherche pour l'URML de champagne Ardenne (2002)

8. C.Maslach, The truth about burnout. San Fransisco:Ed. jossey bass, 1st Ed, p200. (1997)

9. D.Truchot. Le burnout des médecins généralistes de Poitou-Charentes, Rapport de recherche pour l'Union Régionale des Médecins Libéraux de Poitou-Charentes. Université de Poitiers, p99. (2004)

10. E.Ogus, E. Greenglass, R. J. Burke, Gender-role differences, work stress and depersonalization. J. Soc. Behav. Pers,5, 387-398. (1990)

11. J. Glasberg \& al., Prevalence of the burnout syndrome among Brazilian medical oncologists.Rev Assoc Med Bras ; 53(1): 85-9 (2007)

12. R.S.Paffenbarger, R.T.Hyde, A.L.Wing: Physical activity and physical fitness as determinants of health and longevity. In : C.Bouchards, T.Shepard, J.Stephens, R.Sutton, B.D.McPherson (eds), Exercise, Fitness, \& Health. Champaign, IL: Human Kinetics; 3348.( 1990)

13. C.Bouchard: Discussion: Heredity, fitness, and health. In: C.Bouchard, R.J. Shepard, T.Stephens, J.R.Sutton, B.D. McPherson (eds), Exercise, Fitness, \& Health. Champaign, IL: Human Kinetics; 147-153. (1990)

14. R.P. Claytor: Stress reactivity: Hemodynamic adjustments in trained and untrained humans. Medicine and Science in Sports and Exercise; 23: 873-881. (1991)

15. M.S.Sothmann, T.S.Horn, B.A.Hart, A.B. Gustafson: Comparison of discrete cardiovascular fitness groups on plasma catecholamine and selected behavioral responses to psychological stress. Psychophysiology; 24 : 47-54. (1987)

16. C.LCarmack, M.Amaral-Melendez, E.Bourdreaux, et al.: Exercise as a component in the physical and psychological rehabilitation of hemodialysis patients. International Journal of Rehabilitation and Health; 1: 13-23. (1995)

17. W.E.Sime : Exercise in the prevention and treatment of depression. In: Morgan W.P., Godston S.E. (eds), Exercise and Mental Health. Washington, D.C. Hemisphere Publishing Corporation; 145-152 (1987)

18. W.P.Morgan: Affective beneficience of vigourous physical activity. Medicine and Science in Sports and Exercise; $17: 94-100$ (1985)

19. A. Badoux, and D. schmidt-valley. La spiritualité une ressource aussi pour les soignants. Haute Ecole de la Santé La source. (2007)

20. C.Delgado, Sense of coherence, spirituality, stress, and quality of life in chronic illness. Journal of Nursing Scholarship, 39(3), 229-234 (2007)
21. J. Rowold, Effects of spiritual well-being on subsequent happiness, psychological well-being, and stress. Journal of Religion and Health, 50(4), 950-963 (2011)

22. I.Tuck, R.Alleyne, \& W.Thinganjana, Spirituality and stress management in healthy adults. Journal of Holistic Nursing, 24, 245-253 (2006)

23. G.G.Ano, \& E.B. Vasconcelles. Religious coping and psychological adjustment to stress: A meta-analysis. Journal of Clinical Psychology, 61(4),461-480. (2005)

24. R.A. Carleton, P.Esparza, P.J.Thaxter, \& K.E.Grant, Stress, religious coping ressources, and depressive symptoms in an urban adolescent sample. Journal for the Scientific Study of Religion, 47(1), 113-121. (2008)

25. Y.Kim, \& L.Seidlitz, Spirituality moderates the effect of stress on emotional and physical adjustment. Personality and Individual Differences, 32(8), 1377-1390 (2002)

26. J. A.Calicchia, \& L.Graham. Assessing the relationship between spirituality, life stressors, and social ressources: Buffers of stress in graduate students. North American Journal of Psychology, 8(2),307-320 (2006)

27. H.Wetherbe, J.Robinson, D.J.Kurpius, S.Berfort, C.Foley, M.Nicpon, E.Hull-Blanks, S.Sollenberger, \& L.Huser. Spirituality among college freshmen : Relationships to self-esteem, body image, and stress. Counselling and Values, 52, 55-70 (2007)

28. S.Cotton, K.Zebracki, S. L Rosenthal, J.Tsevat, \& D. Drotar, Religion/spirituality and adolescent health outcomes: A review. Journal of Adolescent Health, 38, 472-480 (2006)

29. M.I. Pearce, T. D. Little, \& J.E. Perez, Religiousness and depressive symptoms among adolescents. Journal of Clinical Child \& Adolescent Psychology, 32(2), 267-276 (2003) 